\section{Glass Penetration Used to Repair Cracks in Alumina}

The healing of cracks in ceramic materials can be aided through heat treatment, densifying the material and increasing its strength. In the February issue of the Journal of the American Ceramic Society (p. 491; DOI: 10.1111/j.1551-2916.2005.00086.x), M.-C. Chu and co-workers at the Korean Research Institute of Standards and Science have reported the use of borosilicate glass to heal cracks in alumina, increasing the strength of the material to a value higher than crack-free alumina.

Previous work on the silicon carbide/ silica system showed that residual compression, induced by a coefficient of thermal expansion (CTE) mismatch, contributes to strengthening. For this study, to
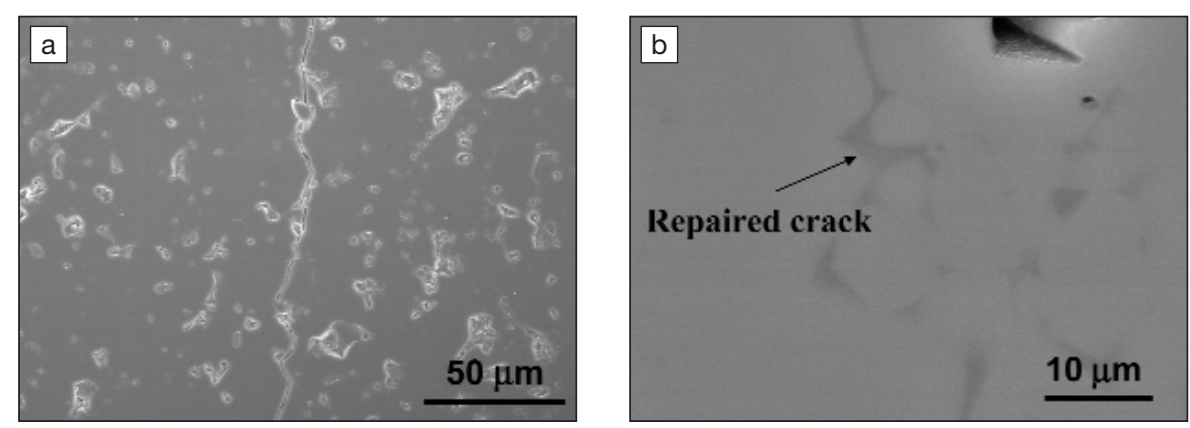

Figure 1. Field-emission scanning electron microscopy of crack morphologies in alumina

before (a) and after (b) penetration by borosilicate glass.

create suitable specimens, plate alumina was machined into flexural bars. Throughthe-thickness cracks were introduced to a depth of $2.5 \mathrm{~mm}$ by Vickers indentation. The introduction then of borosilicate glass, with a CTE lower than that of alumina, created the CTE mismatch desired for residual compression. A piece of borosilicate glass was placed on the crack and heated to $1500^{\circ} \mathrm{C}$ for $15 \mathrm{~min}$. Field-emission scanning electron microscopy shows that the molten glass penetrates through the crack by capillary pressure to fill the crack tip (Figure 1). The glass-filled crack is not continuous to its tip, implying that the alumina grains partially rebonded; this may occur through a solution- precipitation mechanism.

In order to determine their flexural strength, specimens were tested in fourpoint bending, with the cracks in tension. Surprisingly, the glass-penetrated specimens had the same strength as that of the as-machined ones, suggesting complete strength recovery. Optical microscopy reveals that the fracture does not occur through repaired cracks but rather at other points in the alumina, implying that the repaired cracks are stronger than the parent alumina. Further investigation of the crack-repaired specimens after removal of the compressive stress in the crack region also gave strength values comparable to those for the parent alumina. This suggests the repaired cracks can become stronger even without the contribution of the CTE mismatch.

For both as-machined and crackrepaired specimens, the strength as a function of temperature shows that fracture occurs through the repaired crack region only above $750^{\circ} \mathrm{C}$, where glass softening begins. The researchers said that their results can help improve the reliability of alumina components by embedding surface cracks produced during machining or in service with glass.

ADITI RISBUD

For more research news on materials science, access the Materials Research Society Web site:

www.mrs.org/connections 